\title{
Influence of Carbohydrates on In Vitro Production of Enterotoxin by Food Poisoning Strains of Clostridium perfringens
}

\author{
(Received September 11, 1978) \\ Takashi Uemura and Yuko Hamasaki \\ (College of Agriculture, University of Osaka Prefecture: \\ 4-804, Mozu Ume-machi, Sakai, Osaka)
}

\begin{abstract}
Sporulation and enterotoxin production of food poisoning strains of Clostridium perfringens type $\mathbf{A}$ in sporulation media containing carbohydrates were investigated. A slightly modified Duncan and Strong sporulation medium (BM1) and one without soluble starch (BM2) were employed as basal media. BMI consisted of proteose peptone $(1.8 \%)$, yeast extract $(0.2 \%)$, sodium thioglycolate $(0.05 \%)$, dibasic sodium phosphate $\left(\mathrm{Na}_{2} \mathrm{HPO}_{4} \cdot 12 \mathrm{H}_{2} \mathrm{O}, 1.2 \%\right)$ and soluble starch $(0.4 \%)$.

1. From our stock cultures involved in food poisoning outbreaks, strain NCTC8239 with a normally high sporulation frequency and strain A76 with a low sporulation frequency were chosen and the effect of carbohydrate on sporulation and enterotoxin production of those strains was compared with that of soluble starch. Results were as follows: (a) Strain NCTC8239. Fructose and raffinose ( + , more effective than soluble starch), lactose and galactose $( \pm)$, glucose and sucrose ( - , less effective than soluble starch); (b) Strain A76. Fructose, galactose, raffinose and sucrose $(+)$, lactose $( \pm)$, glucose $(-)$.

2. Each of strains NCTC8239, NCTC8798, S79, A75 and A76 showed approximately the same level in spore numbers in BM2 supplemented by galactose or fructose. As to the amount of enterotoxin determined, however, fructose was more effective than galactose. All strains tested produced more than $24 \mu \mathrm{g} / \mathrm{ml}$ of enterotoxin in BM2 containing fructose at $1 \%$.

3. The $\mathrm{pH}$ value of the final cultures in BM1 was between 5.1 and 6.6 , where a satisfactory amount of enterotoxin was determined. But, a maximum in enterotoxin production in BM1 and BM2 supplemented by a carbohydrate other than glucose was obtained when the $\mathrm{pH}$ value of the final culture dropped to between 5 and 6 . This range of $\mathrm{pH}$ value was easily achieved by reducing the concentration of glucose, but no detectable amount of enterotoxin was yielded in the glucose-containing media. Increasing the concentration of soluble starch in BM2 up to $1.6 \%$ did not always result in an increase in the amount of enterotoxin produced.
\end{abstract}

\section{Introduction}

Clostridium perfringens is widely distributed in nature, food, and the intestinal tracts of man and animals. The prevalence of the organisms in various environments has been studied and reviewed." In $C$. perfringens food poisoning, an enterotoxin is thought to be responsible for the typical symptom, diarrhea. The enterotoxin is synthesized during sporulation of the organisms. ${ }^{21}$ It has been largely accepted that $C$. perfringens can be divided into two types: enterotoxigenic and nonenterotoxigenic strains. Therefore, it is important for food hygiene to clarify the distribution of enterotoxigenic $C$. perfringens and the factors regulating sporulation of the organisms.

In the course of those studies, efforts have been directed towards the development of a satisfactory sporulation medium. ${ }^{\text {s) }}$ N1 Nevertheless, it is still difficult to obtain a satisfactory level of sporulation for many strains and the levels of sporulation in a given strain vary from experiment to experiment. In recent studies on the development of suitable sporulation media for $C$. perfringens, the influence of carbohydrates on sporulation has been investigated: soluble $\operatorname{starch}^{81,4)}$ and slowly fer- 
mentable sugars such as raffinose and melibiose $^{81}$ have been recommended.

In this paper, we report that an addition of some carbohydrates other than glucose to the sporulation media enhances sporulation of C. perfringens

\section{Materials and Methods}

\subsection{Strains}

A total of 5 stock cultures in a cooked meat medium of $C$. perfringens type $\mathrm{A}$ in our laboratory were used. All these strains had been implicated in food poisoning outbreaks. Single colonies of each strain were fished from plates of CW egg-yolk agar (Nissui Seiyaku, Tokyo), inoculated into $10 \mathrm{ml}$ of cooked meat medium (Difco Laboratories, Detroit, Mich) and incubated overnight at $37^{\circ} \mathrm{C}$; the cultures were sealed with liquid paraffin, maintained at room temperature and used throughout the study as stock cultures.

\subsection{Sporulation media}

The sporulation medium of Duncan and Strong" ${ }^{\text {"1 }}$ was slightly modified and used as a control sporulation medium. It consisted of proteose peptone (Difco), 1.8\%, yeast extract (Oriental Kobo Kogyo, Tokyo), 0.2\%; dibasic sodium phosphate, 1.2\%; sodium thioglycolate, $0.05 \%$; soluble starch, $0.4 \%$. To examine the effect of carbohydrates on sporulation of $C$. perfringens the modified Duncan and Strong sporulation medium (BM1) and one without soluble starch (BM2) were used as basal media. A $10 \%$ solution of each carbohydrate was autoclaved for $10 \mathrm{~min}$ at $115^{\circ} \mathrm{C}$ and added to $\mathrm{BM} 1$ and BM2 to obtain indicated concentrations.

\subsection{Carbohydrates}

The following carbohydrates, purchased from Wako Pure Chem., Osaka, were used: galactose, glucose, lactose, raffinose, fructose, soluble starch and sucrose.

\subsection{Culture techniques}

The size of inocula, liquid media and tubes, and the inoculation sequence were similar to those described in the previous paper." A single heat treatment of organisms for $20 \mathrm{~min}$ at $75^{\circ} \mathrm{C}$ was carried out just before incubation for precultures. All incubations were made at $37^{\circ} \mathrm{C}$.

2.5 Determination of cell numbers and enterotoxin contents

Calculations of total cell numbers and spore numbers were performed as previously reported. ${ }^{101}$ Enterotoxin contents were determined by the reversed passive hemagglutination (RPHA) test ${ }^{10 \prime}$ and counterimmunoelectrophoresis. The counterimmunoelectrophoresis was slightly modified from the method previously reported: ${ }^{111}$ glass plates of $5 \times 5 \mathrm{~cm}$ were covered with $5 \mathrm{ml}$ of 196 Special Agar-Noble (Difco) in barbital buffer $(\mu, 0.1 ; \mathrm{pH}, 8.6)$. Parallel rows of wells, $3 \mathrm{~mm}$ in diameter, were punched $0.3 \mathrm{~cm}$ apart. Each set of paired wells received $10 \mu \mathrm{l}$ of test materials and $1: 2$ dilutions of rabbit antiserum. ${ }^{121}$ The electrode vessels contained the same buffer. Counterimmunoelectrophoresis was run for one hour at a constant current of $2 \mathrm{~mA} / \mathrm{cm}$ in the gel.

\section{Results}

Among our stock cultures, strain NCTC8239 consistently showed a high sporulation frequency in sporulation media. Initially, using this strain, we examined the influence of some carbohydrates on sporulation and enterotoxin production. All carbohydrates tested stimulated growth of the organisms. As shown in Table 1 , glucose added to BM1 and BM2 at concentrations of $0.5 \%$ or higher significantly inhibited sporulation. But sporulation and enterotoxin production were encountered both in BM1 and BM2 containing each one of the other carbohydrates. Result in the case of raffinose indicated that higher concentrations in the medium up to $2 \%$ lead to the higher titer of enterotoxin determined. Galactose and lactose at appropriate concentrations resulted in almost the same levels of enterotoxin production as did soluble starch at $0.49 \%$. But, the addition of sucrose to BM1 and BM2 slightly inhibited enterotoxin production.

We further investigated the effects of carbohydrates on sporulation and enterotoxin production using strain A76 which had exhibited a relatively low sporulation frequency among our stock cultures. Table 2 shows the results. An addition of carbohydrates to BM1 and BM2 enhanced sporulation and enterotoxin production by strain A76. The highest level of enterotoxin (BM1+1\% fructose) was the same as that observed in strain NCTC8239 (Table 1). But the optimum conditions for this strain seemed to be somewhat more restricted than 
Table 1. Influence of Carbohydrates on In Vitro Sporulation and Enterotoxin Production of Clostridium perfringens Type A Strain NCTC8239

\begin{tabular}{|c|c|c|c|c|c|c|}
\hline \multicolumn{2}{|c|}{ Carbohydrate } & \multirow{2}{*}{ Basal medium } & \multirow{2}{*}{ Final pH } & \multirow{2}{*}{$\begin{array}{c}\text { Total } \\
\text { cells } \\
\left(\mathrm{ml} \times 10^{6}\right)\end{array}$} & \multirow{2}{*}{$\begin{array}{c}\text { Spore } \\
\text { number } \\
\left(\mathrm{ml} \times 10^{6}\right)\end{array}$} & \multirow{2}{*}{$\begin{array}{l}\text { Entero } \\
\text { toxind } \\
(\mu \mathrm{g} / \mathbf{m l})\end{array}$} \\
\hline Addition of & $9 \%$ & & & & & \\
\hline \multirow[t]{2}{*}{ Glucose } & $\begin{array}{l}0.1 \\
0.5 \\
1.0 \\
2.0\end{array}$ & BM1 a) & $\begin{array}{l}6.3 \\
5.4 \\
4.8 \\
4.8\end{array}$ & $\begin{array}{l}110 \\
930 \\
550 \\
500\end{array}$ & $\begin{array}{r}10 \\
0 \\
0 \\
0\end{array}$ & $\begin{array}{l}0.48 \\
0.1 \\
0 \\
0.16\end{array}$ \\
\hline & $\begin{array}{l}1.0 \\
2.0 \\
4.0\end{array}$ & $\mathrm{BM} 2^{\mathrm{b})}$ & $\begin{array}{l}4.8 \\
4.8 \\
4.8\end{array}$ & $\begin{array}{r}740 \\
1,100 \\
740\end{array}$ & $\begin{array}{l}2.5 \\
0 \\
0\end{array}$ & $\begin{array}{l}0.48 \\
0.97 \\
0.24\end{array}$ \\
\hline \multirow[t]{2}{*}{ Fructose } & $\begin{array}{l}0.1 \\
0.5 \\
1.0 \\
2.0\end{array}$ & BM1 & $\begin{array}{l}6.1 \\
5.3 \\
5.3 \\
5.2\end{array}$ & $\begin{array}{r}72 \\
89 \\
66 \\
250\end{array}$ & $\begin{array}{r}51 \\
47 \\
25 \\
150\end{array}$ & $\begin{array}{l}48 \\
32 \\
64 \\
48\end{array}$ \\
\hline & $\begin{array}{l}1.0 \\
2.0 \\
4.0\end{array}$ & BM2 & $\begin{array}{l}5.7 \\
5.8 \\
4.9\end{array}$ & $\begin{array}{l}120 \\
140 \\
130\end{array}$ & $\begin{array}{l}77 \\
72 \\
37\end{array}$ & $\begin{array}{l}32 \\
32 \\
0.75\end{array}$ \\
\hline \multirow[t]{2}{*}{ Galactose } & $\begin{array}{l}0.1 \\
0.5 \\
1.0 \\
2.0\end{array}$ & BM1 & $\begin{array}{l}6.5 \\
6.1 \\
5.4 \\
5.2\end{array}$ & $\begin{array}{r}57 \\
290 \\
250 \\
88\end{array}$ & $\begin{array}{r}43 \\
270 \\
220 \\
13\end{array}$ & $\begin{array}{l}24 \\
32 \\
32 \\
16\end{array}$ \\
\hline & $\begin{array}{l}1.0 \\
2.0 \\
4.0\end{array}$ & BM2 & $\begin{array}{l}6.6 \\
5.9 \\
5.4\end{array}$ & $\begin{array}{l}190 \\
300 \\
160\end{array}$ & $\begin{array}{r}170 \\
190 \\
42\end{array}$ & $\begin{array}{r}16 \\
16 \\
4\end{array}$ \\
\hline \multirow[t]{2}{*}{ Lactose } & $\begin{array}{l}0.1 \\
0.5 \\
1.0 \\
2.0\end{array}$ & $\begin{array}{l}\vdots \\
t \cdots \\
\therefore \\
\vdots\end{array}$ & $\begin{array}{l}6.3 \\
5.2 \\
5.2 \\
5.2\end{array}$ & $\begin{array}{l}130 \\
160 \\
230 \\
420\end{array}$ & $\begin{array}{r}100 \\
18 \\
12 \\
26\end{array}$ & $\begin{array}{l}32 \\
16 \\
16 \\
16\end{array}$ \\
\hline & $\begin{array}{l}1.0 \\
2.0 \\
4.0\end{array}$ & BM2 & $\begin{array}{l}5.3 \\
5.2 \\
5.3\end{array}$ & $\begin{array}{l}150 \\
230 \\
200\end{array}$ & $\begin{array}{l}11 \\
33 \\
65\end{array}$ & $\begin{array}{l}24 \\
24 \\
32\end{array}$ \\
\hline \multirow[t]{2}{*}{ Sucrose } & $\begin{array}{l}0.1 \\
0.5 \\
1.0 \\
2.0\end{array}$ & BM1 & $\begin{array}{l}6.1 \\
5.1 \\
4.8 \\
4.8\end{array}$ & $\begin{array}{l}620 \\
350 \\
400 \\
420\end{array}$ & $\begin{array}{r}310 \\
59 \\
81 \\
85\end{array}$ & $\begin{array}{c}30 \\
12 \\
2.5 \\
1\end{array}$ \\
\hline & $\begin{array}{l}1.0 \\
2.0 \\
4.0\end{array}$ & BM2 & $\begin{array}{l}4.8 \\
4.8 \\
4.8\end{array}$ & $\begin{array}{l}280 \\
310 \\
210\end{array}$ & $\begin{array}{l}68 \\
65 \\
33\end{array}$ & $\begin{array}{r}6 \\
1 \\
16\end{array}$ \\
\hline \multirow[t]{2}{*}{ Raffinose } & $\begin{array}{l}0.1 \\
0.5 \\
1.0 \\
2.0\end{array}$ & BM1 & $\begin{array}{l}6.1 \\
5.3 \\
5.1 \\
5.1\end{array}$ & $\begin{array}{r}260 \\
490 \\
92 \\
86\end{array}$ & $\begin{array}{r}240 \\
290 \\
73 \\
72\end{array}$ & $\begin{array}{l}40 \\
40 \\
64 \\
64\end{array}$ \\
\hline & $\begin{array}{l}1.0 \\
2.0 \\
4.0\end{array}$ & BM2 & $\begin{array}{l}5.4 \\
5.2 \\
5.6\end{array}$ & $\begin{array}{l}220 \\
260 \\
110\end{array}$ & $\begin{array}{r}160 \\
210 \\
72\end{array}$ & $\begin{array}{l}48 \\
48 \\
32\end{array}$ \\
\hline \multirow{2}{*}{\multicolumn{2}{|c|}{ Without }} & $\overline{B M 1}$ & 6.7 & 120 & 86 & 26 \\
\hline & & BM2 & 7.4 & 15 & 12 & 0.85 \\
\hline
\end{tabular}

4) The sporulation medium of Duncan and Strong ${ }^{3 /}$ was slightly modified.

Ingredients: Proteose peptone (1.8\%); yeast extract $(0.2 \%)$; sodium thioglycolate $(0.05 \%)$; soluble starch $(0.4 \%)$; dibasic sodium phosphate $(1.2 \%)$

b) BM1 without soluble starch c) Less than $0.1 \mu \mathrm{g} / \mathrm{ml}$

d) Spore and total cell numbers and amounts of enterotoxin were determined in duplicate 
Table 2. Influence of Carbohydrates on In Vitro Sporulation and Enterotoxin Production of Clostridium perfringens Type A Strain A76

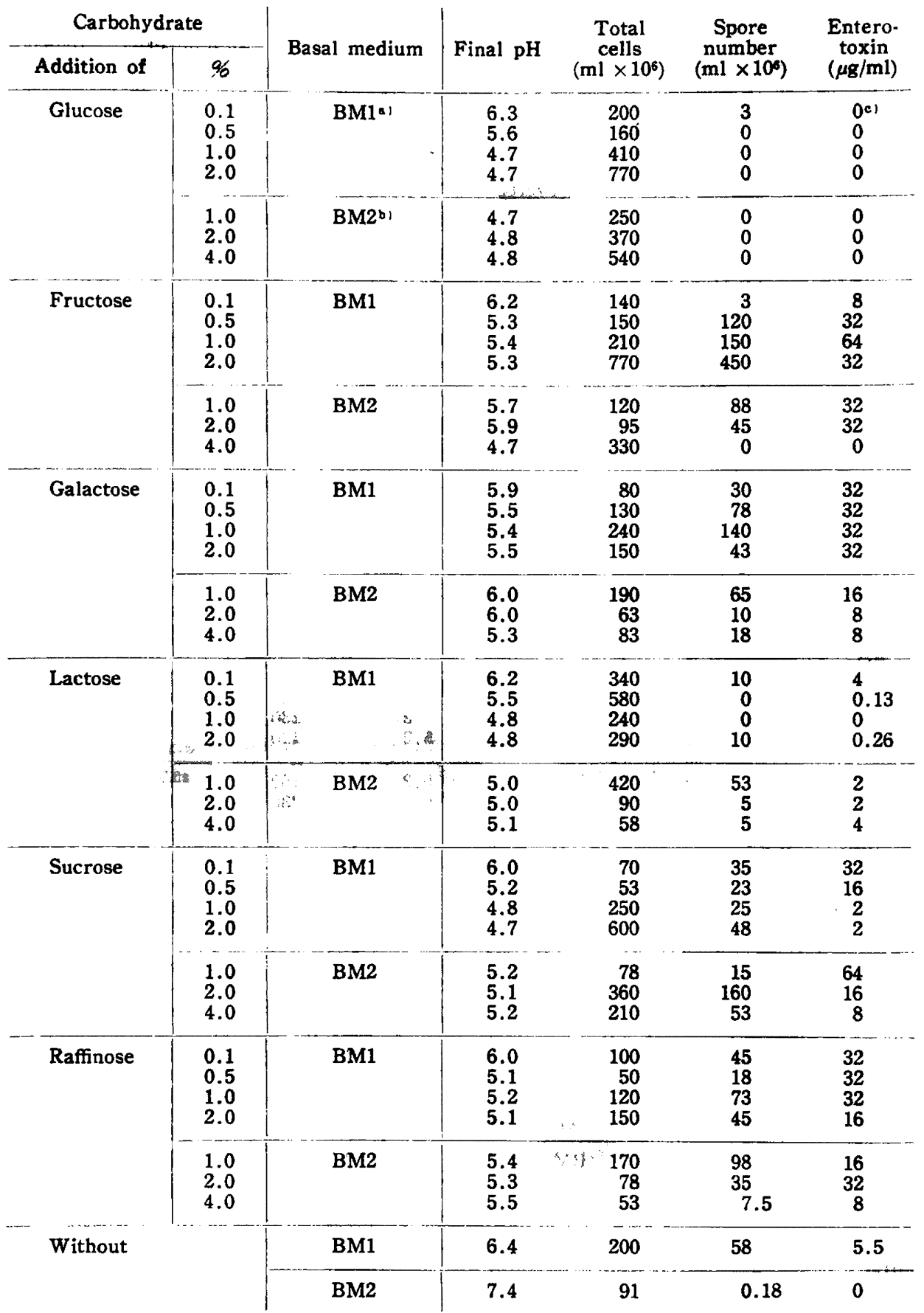

- Ingredients: Proteose peptone (1.8\%); yeast extract (0.2\%); sodium thioglycolate $(0.05 \%)$; soluble starch $(0.4 \%)$; dibasic sodium phosphate $(1.2 \%)$

b) BM1 without soluble starch

c) Less than $0.1 \mu \mathrm{g} / \mathrm{ml}$ 
Table 3. Sporulation and Enterotoxin Production of Clostridium perfringens Type A Strains A75, S79 and NCTC8798 in Modified Duncan and Strong Sporulation Medium without Soluble Starch Supplemented by Galactose or Fructose at 1\%

\begin{tabular}{|c|c|c|c|c|c|}
\hline Strain & Addition of & Final $\mathrm{pH}$ & $\begin{array}{c}\text { Total } \\
\text { cells } \\
\left(\mathrm{ml} \times 10^{6}\right)\end{array}$ & $\begin{array}{c}\text { Spore } \\
\text { number } \\
\left(\mathrm{ml} \times 10^{6}\right)\end{array}$ & $\begin{array}{c}\text { Entero- } \\
\text { toxin } \\
(\mu \mathrm{g} / \mathrm{ml})\end{array}$ \\
\hline \multirow[t]{3}{*}{ A75 } & Galactose & 6.3 & 200 & 59 & 8 \\
\hline & Fructose & 5.3 & 360 & 39 & 24 \\
\hline & Soluble starch $(0.4 \%)^{\text {a }}$ & 6.2 & 360 & 3.8 & 8 \\
\hline \multirow[t]{3}{*}{ S79 } & Galactose & 5.8 & 97 & 43 & 8 \\
\hline & Fructose & 5.7 & 64 & 45 & 32 \\
\hline & Soluble starch $(0.4, j)$ & 6.4 & 410 & 79 & 12 \\
\hline \multirow[t]{3}{*}{ NCTC8798 } & Galactose & 6.9 & 110 & 54 & 32 \\
\hline & Fructose & 6.3 & 100 & 78 & 64 \\
\hline & Soluble starch $(0.4 \%)$ & 6.6 & 160 & 100 & 32 \\
\hline
\end{tabular}

a) Control

those for strain NCTC8239.

From these results, BM2 containing 19\% fructose or galactose was chosen for testing sporulation and enterotoxin production by the rest of the strains. As shown in Table 3, the use of fructose resulted in the highest level of enterotoxin production. But the use of fructose and galactose resulted in nearly the same numbers of spores for each strain. Fructose reduced the $\mathrm{pH}$ values of final cultures to a greater degree than did galactose.

Strains NCTC8239 and A76 neither sporulated nor produced sufficient amounts of enterotoxin in the medium containing glucose at $1 \%$, when the $\mathrm{pH}$ of the cultures dropped to 4.75 or lower. Fructose, when added to the medium at $4 \%$, reduced the $\mathrm{pH}$ of the final cultures to 4.7 (NCTC8239) and 4.9 (A76) and resulted in no enterotoxin production (Tables 1 and 2). A possibility remained that glucose could be used as energy source for completion of sporulation by $C$. perfringens when added to BM2 at less than 196 to sustain the $\mathrm{pH}$ of the culture at a level higher than 5 . The addition of glucose at $0.6 \%$ or less, resulted in the $\mathrm{pH}$ values of $\mathbf{5 . 5}$ or over in the final cultures of all strains and an abundant growth of vegetative cells. Nevertheless, sporulation and enterotoxin production were completely inhibited (Table 4).

\section{Discussion}

C. perfringens sporulates poorly in many laboratory culture media, though it may sporulate more easily in the intestinal tract. In vitro sporulation of $C$. perfringens has been examined and discussed from different viewpoints: nutritional requirements; culture techniques; ${ }^{131}$ genetical aspects, ${ }^{141,151}$ and changes in properties of ability to sporulate. ${ }^{16)}$ The viewpoint of nutritional requirements has received much more attention than any other.

DS medium and a minor modification have been widely used in many laboratories. Because increasing the content of proteose peptone from 1.5 to $1.8 \%$ had been found to result in higher spore yields than the original DS medium, we used BM1 as the reference sporulation medium as well as the basal medium for the sporulation media supplemented by carbohydrates. Results dealing with the influence of carbohydrates on the sporulation of $C$. perfringens have been published by some researchers. Ellner" and Duncan and Strong ${ }^{3 !}$ employed starch. Labbe and Duncan observed that variations in the ability of a strain depended on the source of the starch used, and that soluble starches were better than potato, corn, or arrowroot starch. ${ }^{171}$ Labbe and Duncan also postulated that amilolytic production of short-chain glucose polymers provided the energy for completion of sporulation. ${ }^{18)}$ Nakamura and Nishida suggested the importance of carbohydrates on sporulation of $C$. perfringens and recommended the use of slowly fermentable sugars such as raffinose and melibiose 
Table 4. Sporulation and Enterotoxin Production of Food Poisoning Strains of Clostridium perfringens in Modified Duncan and Strong Spolulation Medium without Soluble Starch Supplemented by Glucose or Soluble Starch at Different Concentrations

\begin{tabular}{|c|c|c|c|c|c|c|}
\hline \multirow{2}{*}{ Strain } & \multicolumn{2}{|c|}{ Carbohydrate } & \multirow{2}{*}{ Final $\mathrm{pH}$} & \multirow{2}{*}{$\begin{array}{c}\text { Total } \\
\text { cells } \\
\left(\mathrm{ml} \times 10^{6}\right)\end{array}$} & \multirow{2}{*}{$\begin{array}{c}\text { Spore } \\
\text { number } \\
\left(\mathrm{ml} \times 10^{6}\right)\end{array}$} & \multirow{2}{*}{$\begin{array}{c}\text { Entero- } \\
\text { toxin } \\
(\mu \mathrm{g} / \mathrm{ml})\end{array}$} \\
\hline & Addition of & $\%$ & & & & \\
\hline \multirow[t]{2}{*}{ NCTC8239 } & Glucose & $\begin{array}{l}0.2 \\
0.4 \\
0.6 \\
0.8 \\
1.0\end{array}$ & $\begin{array}{l}6.8 \\
6.3 \\
5.9 \\
5.1 \\
4.7\end{array}$ & $\begin{array}{l}530 \\
480 \\
480 \\
290 \\
350\end{array}$ & $\begin{array}{l}0 \\
0 \\
0 \\
0 \\
0\end{array}$ & $\begin{array}{l}0 \times 1 \\
0 \\
0 \\
0 \\
0\end{array}$ \\
\hline & Soluble starch & $\begin{array}{l}0 \\
0.4 \\
0.8 \\
1.2 \\
1.6\end{array}$ & $\begin{array}{l}7.3 \\
6.4 \\
5.7 \\
5.5 \\
5.3\end{array}$ & $\begin{array}{r}28 \\
240 \\
140 \\
220 \\
280\end{array}$ & $\begin{array}{l}2.8 \\
190 \\
120 \\
210 \\
240\end{array}$ & $\begin{array}{r}0 \\
32 \\
32 \\
32 \\
32\end{array}$ \\
\hline \multirow[t]{2}{*}{ NCTC8798 } & Glucose & $\begin{array}{l}0.2 \\
0.4 \\
0.6 \\
0.8 \\
1.0\end{array}$ & $\begin{array}{l}6.7 \\
6.2 \\
5.5 \\
4.8 \\
4.6\end{array}$ & $\begin{array}{l}780 \\
340 \\
530 \\
410 \\
450\end{array}$ & $\begin{array}{l}0 \\
0 \\
0 \\
0 \\
0\end{array}$ & $\begin{array}{l}0 \\
0 \\
0 \\
0 \\
0\end{array}$ \\
\hline & Soluble starch & $\begin{array}{l}0 \\
0.4 \\
0.8 \\
1.2 \\
1.6\end{array}$ & $\begin{array}{l}7.4 \\
6.7 \\
6.0 \\
5.2 \\
5.0\end{array}$ & $\begin{array}{r}87 \\
140 \\
200 \\
530 \\
650\end{array}$ & $\begin{array}{c}0 \\
7.5 \\
33 \\
1.3 \\
28\end{array}$ & $\begin{array}{l}0 \\
8 \\
8 \\
8 \\
4\end{array}$ \\
\hline \multirow[t]{2}{*}{ S79 } & Glucose & $\begin{array}{l}0.2 \\
0.4 \\
0.6 \\
0.8 \\
1.0\end{array}$ & $\begin{array}{l}6.7 \\
6.3 \\
5.7 \\
5.2 \\
5.0\end{array}$ & $\begin{array}{r}290 \\
380 \\
1,000 \\
520 \\
700\end{array}$ & $\begin{array}{l}0 \\
0 \\
0 \\
0 \\
0\end{array}$ & $\begin{array}{l}0 \\
0 \\
0 \\
0 \\
0\end{array}$ \\
\hline & Soluble starch & $\begin{array}{l}0 \\
0.4 \\
0.8 \\
1.2 \\
1.6\end{array}$ & $\begin{array}{l}7.4 \\
6.8 \\
6.4 \\
6.3 \\
6.3\end{array}$ & $\begin{array}{r}27 \\
58 \\
140 \\
85 \\
25\end{array}$ & $\begin{array}{r}2 \\
48 \\
130 \\
73 \\
13\end{array}$ & $\begin{array}{r}0 \\
8 \\
8 \\
8 \\
16\end{array}$ \\
\hline \multirow[t]{2}{*}{ A75 } & Glucose & $\begin{array}{l}0.2 \\
0.4 \\
0.6 \\
0.8 \\
1.0\end{array}$ & $\begin{array}{l}6.9 \\
6.3 \\
5.9 \\
4.8 \\
4.6\end{array}$ & $\begin{array}{l}380 \\
480 \\
490 \\
620 \\
130\end{array}$ & $\begin{array}{l}7.5 \\
0 \\
0 \\
0 \\
0\end{array}$ & $\begin{array}{l}0.13 \\
0 \\
0 \\
0 \\
0\end{array}$ \\
\hline & Soluble starch & $\begin{array}{l}0 \\
0.4 \\
0.8 \\
1.2 \\
1.6\end{array}$ & $\begin{array}{l}7.4 \\
6.6 \\
5.5 \\
4.9 \\
4.8\end{array}$ & $\begin{array}{r}48 \\
390 \\
560 \\
550 \\
540\end{array}$ & $\begin{array}{l}1.5 \\
2.5 \\
15 \\
13 \\
35\end{array}$ & $\begin{array}{l}0.13 \\
0.13 \\
2 \\
2 \\
2\end{array}$ \\
\hline \multirow[t]{2}{*}{ A76 } & Glucose & $\begin{array}{l}0.2 \\
0.4 \\
0.6 \\
0.8 \\
1.0\end{array}$ & $\begin{array}{l}6.8 \\
6.3 \\
5.9 \\
4.9 \\
4.8\end{array}$ & $\begin{array}{l}180 \\
230 \\
400 \\
460 \\
560\end{array}$ & $\begin{array}{l}0 \\
0 \\
0 \\
0 \\
0\end{array}$ & $\begin{array}{l}0 \\
0 \\
0 \\
0 \\
0\end{array}$ \\
\hline & Soluble starch & $\begin{array}{l}0 \\
0.4 \\
0.8 \\
1.2 \\
1.6\end{array}$ & $\begin{array}{l}7.4 \\
6.4 \\
5.4 \\
4.9 \\
4.7\end{array}$ & $\begin{array}{r}70 \\
45 \\
230 \\
300 \\
680\end{array}$ & $\begin{array}{l}0 \\
2.8 \\
0 \\
2.5 \\
0\end{array}$ & $\begin{array}{l}0.26 \\
4 \\
2 \\
2 \\
2\end{array}$ \\
\hline
\end{tabular}

2) Less than $0.1 \mu \mathrm{g} / \mathrm{ml}$ 
to obtain spores. ${ }^{81}$

We expected, at first, that the addition of carbohydrates to sporulation media would result in an inhibitory effect on the sporulation of C. perfringens. Because Gyobu and Kodama ${ }^{6}$ had already observed that strain NCTC8798 neither sporulated nor produced enterotoxin in a medium consisting of proteose peptone (1\%), yeast extract (0.5\%), sodium thioglycolate $(0.1 \%)$ and carbohydrate (glucose, sucrose, lactose, fructose, raffinose, or maltose; $0.5 \%$ ). The final $\mathrm{pH}$ of their cultures dropped to between 4.1 and 4.6. The use of glucose, in the present study, gave the expected results (Tables 1,2 and 4); the addition of glucose to BM1 stimulated an abundant growth of vegetative cells which resulted in the decrease of $\mathrm{pH}$ lower than 5, and completely inhibited sporulation and enterotoxin production. The use of sucrose at the concentration employed also slightly inhibited enterotoxin production (Table 1). But inhibition was not observed in the experiments with the other carbohydrates at concentrations up to $2 \%$ (Table 1). As pointed out by Nakamura and Nishida, ${ }^{81}$ we found that the use of raffinose was better than soluble starch for sporulation of $C$. perfringens. Results given in Table 1 were obtained in NCTC8239. As this strain was known to sporulate consistently well in many kinds of sporulation media, in the subsequent experiments, we examined sporulation and the ability to produce enterotoxin by strain A76 which was known to be relatively poor sporulator among our stock cultures implicated in food poisoning outbreaks. The contradictory results of the effect of carbohydrates were more clearly shown (Table 2). Strain A76 poorly sporulated in BM2 and did not sporulate in the presense of glucose; whereas fructose, raffinose and galactose drastically enhanced sporulation of this strain. This beneficial effect of galactose and fructose was observed in other strains (Table 3), as well.

The addition of much carbohydrate to sporulation media had been thought to stimulate an abundant growth of vegatative cells, and lead to a quick drop in the $\mathrm{pH}$ of the culture followed by poor sporulation. This was found to be largely acceptable (Tables 1 and 2); in cultures with $\mathrm{pH}$ values lower than 5 , entero- toxin production was shown to be greatly inhibited in all strains by all carbohydrates. But the repression of the sporulation of $C$. perfringens can not be explained simply as a result of the decrease of the $\mathrm{pH}$ in the culture. The $\mathrm{pH}$ values of final cultures in BM1 and BM2 supplemented by carbohydrates other than glucose came near to 5 in many cases but produced considerable amounts of enterotoxin, whereas sporulation was completely inhibited in cultures supplemented by glucose even when $\mathrm{pH}$ values were maintained at 5.5 (Tables 1,2 and 4). Glucose or some metabolites of glucose, or both may play a role in the inhibition of sporulation as known in bacilli and clostridia. ${ }^{191}$

The number of spores did not correlate with the amount of enterotoxin determined. Strains A75, A76, S79 and NCTC8798 yielded almost the same numbers of refractile spores in both media containing galactose or fructose, but higher concentrations of enterotoxin were determined in the cultures in the medium containing fructose for those strains. As reported previously, ${ }^{91}$ a higher RPHA titer was obtained when the culture was kept overnight in a refrigerator, Labbe et al. ${ }^{17)}$ noticed this inconsistency; in the sporulation medium containing wheat starch a high number of heat resistant spores were produced, but the enterotoxin yields were poor. In the medium supplemented by fructose, the yield of enterotoxin per cell might be high. Or enterotoxin may be easily released from the sporulated cells. This observation was of great interest, however the present study did not bring out any clear evidence for which explanation is correct.

Sporulation of $C$. perfringens did not always occur in the media supplemented by carbohydrates. The buffer action with salt such as dibasic sodium phosphate plays another important role. The optimal concentration of carbohydrate in the sporulation medium depends on the other ingredients of the basal medium employed and on the strain tested. The addition of fructose to the basal medium of BM2 at $1 \%$ was found to be best for enterotoxin production of the food poisoning strains tested; all strains tested produced more than $24 \mu \mathrm{g} / \mathrm{ml}$ of enterotoxin. This amount of enterotoxin can be easily detected by ordinary 
immunological and biological methods $201,21 !$ without laborious concentration procedures.

Studies on the development of sporulation media will be continued until the sole factor(s) involved in the sporulation of $C$. perfringens can be clarified. Though it did not determine whether BM2 supplemented by fructose could be used for testing enterotoxin production of other strains isolated from different sources, this study opened the use of carbohydrates other than glucose in sporulation media suitable for $C$. perfringens and pointed out the $\mathrm{pH}$ values of final cultures as a useful indicator for the choice of concentration of carbohydrate to be added to the sporulation media suitable for a given strain. This also suggested the possible role of mono- and di-saccharides, digestive products of carbohydrates, on in vivo sporulation followed by the production of enterotoxin of $C$. perfringens.

\section{References}

1) Walker, H. W.: Food Science and Nutrition, 7, 71 (1975).

2) Duncan, C.L., Strong, D. H., Sebald, M.: J. Bacteriol., 110, 378 (1972).

3) Duncan, C. L., Strong, D. H.: Appl. Microbiol., 16, 82 (1968).

4) Ellner, P. D.: J. Bacteriol., 71, 495 (1956).
5) Gyobu, Y., Kodama, H.: J. Food Hyg. Soc. of Japan, 17, 219 (1976).

6) Kim, C. H.: Appl. Microbiol., 15, 871 (1967).

7) Nishida, S., Seo, N., Nakagawa, M.: Appl. Microbiol., 17, 303 (1969).

8) Nakamura, S., Nishida, S.: J. Med. Microbiol., 7, 451 (1974).

9) Uemura, T.: J. Appl. Bacteriol., 44, 411 (1978).

10) Uemura, T., Sakaguchi, G., Riemann, H.P.: Appl. Microbiol., 26, 381 (1973).

11) Skjelkvåle, R., Uemura, T.: J. Appl. Bacteriol., 42, 355 (1977).

12) Sakaguchi, G., Uemura, T., Riemann, H.P.: Appl. Microbiol., 26, 762 (1973).

13) Perkins, W. E.: J. Appl. Bacteriol., 28, 1 (1965).

14) Stewart, A. W., Johnson, M. G.: J. Gen. Microbiol., 103, 45 (1977).

15) Sebald, M., Costilow, R. N.: Appl. Microbiol., 29, 1 (1975).

16) Uemura, T.: J. Food Hyg. Soc. of Japan, 19, 462 (1978).

17) Labbe, R., Somers, E., Duncan, C.: Appl. Environ. Microbiol., 31, 455 (1976).

18) Labbe, R. G., Duncan, C. L.: Appl. Microbiol., 29, 345 (1975).

19) Hachisuka, Y., Horikoshi, K. ed.: "Permanentform organisms [in Japanese, Taikyu-gata Saibo]" (1976) Iwanami-shoten, Tokyo.

20) Genigeorgis, C., Sakaguchi, G., Riemann, H.: Appl. Microbiol., 26, 111 (1973).

21) Uemura, T.: Japan. J. Bacteriol., 29, 345 (1974). 